\title{
Taking control
}

$I_{\text {siten }}^{\mathrm{n}}$ $n$ this issue of the Canadian Journal of Infectious Diseases, Salama et al (pages 104-109) describe their experience in the development of an antimicrobial use program. Through a combination of restrictive formulary practices, infection specific guidelines and accelerated switch from parenteral or oral therapy, they documented savings at their institution of over $\$ 300,000$ per year. This was a multidisciplinary program that included infectious diseases, pharmacy, microbiology, nursing and administration departments. The savings achieved were certainly much greater than the cost to develop or maintain the program.

These observations are not new. Indeed, the Infectious Diseases Society of America (IDSA) proposed a multidisciplinary team approach to antimicrobial review and optimizing therapy almost 10 years ago (1). The IDSA document clearly and intentionally removed antimicrobial use decisions from the realm of individual physician choice to a multidisciplinary, facility based group directed by an appropriately trained and reimbursed infectious disease physician. There is substantial documentation of the cost effectiveness of such programs, including other Canadian reports (2).

Why, then, are highly restrictive antimicrobial policies and programs not in place in all institutions in Canada? The majority of institutions have some programs for antimicrobial control, but individual physician choice with limited external direction remains the norm. Yet few physicians outside of infectious disease have the depth of knowledge and experience in microbiology, antimicrobial resistance, clinical medicine and pharmacological parameters to have true expertise in antimicrobial use. This is neither a criticism of our colleagues nor an argument for elitism - it is a reality of medical practice in a time of rapidly expanding knowledge base and constantly shifting epidemiology.

Current antimicrobial use programs generally evolved in response to escalating costs of newer antimicrobials added to formularies from the mid-1980s onwards. While limited clinical information, when available, was used to justify preferred antimicrobial regimens, the real imperative for these programs was unquestionably cost restraint. Now, with increasing evidence that intensity of antimicrobial pressure correlates with antimicrobial resistance development, and as our therapeutic options narrow because of resistant organisms, the imperatives for such programs will shift towards resistance control.

The evidence is clear that optimal antimicrobial use requires highly structured and controlled antimicrobial programs. Such programs should be present in all acute care facilities. We should not feel compelled to apologize to our colleagues in other disciplines for restricting their access to and use of antimicrobials. Intelligent, concerned physicians in 1996 must acknowledge the necessity for these restrictive programs. While each facility must ensure multidisciplinary input in their programs, the ultimate direction and decisions with respect to clinical use must rest with infectious diseases physicians with appropriate training and expertise in these issues. On our part, we must use evidence based approaches for these programs and ensure appropriate dialogue with our colleagues in the development and operation of such programs. Antimicrobial use programs are essential for optimal patient care in health care facilities and will minimize cost. As such, facilities should ensure that resources are provided to allow optimal program function, including appropriate reimbursement of physicians who do the work of the programs.

\section{REFERENCES}

1. Marr JJ, Moffet HL, Hunin CM. Guidelines for improving the use of antimicrobial agents in hospitals: a statement by the Infectious Diseases Society of America. J Infect Dis 1988;5:869-76.

2. Pitre M, Zamin M, Conly JM. Development of a route conversion program for antimicrobial agents at the Toronto Hospital. Can J Infect Dis 1995;6(Suppl A): 18A-9A. 


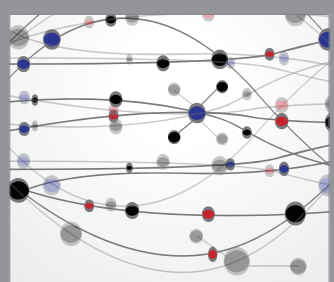

The Scientific World Journal
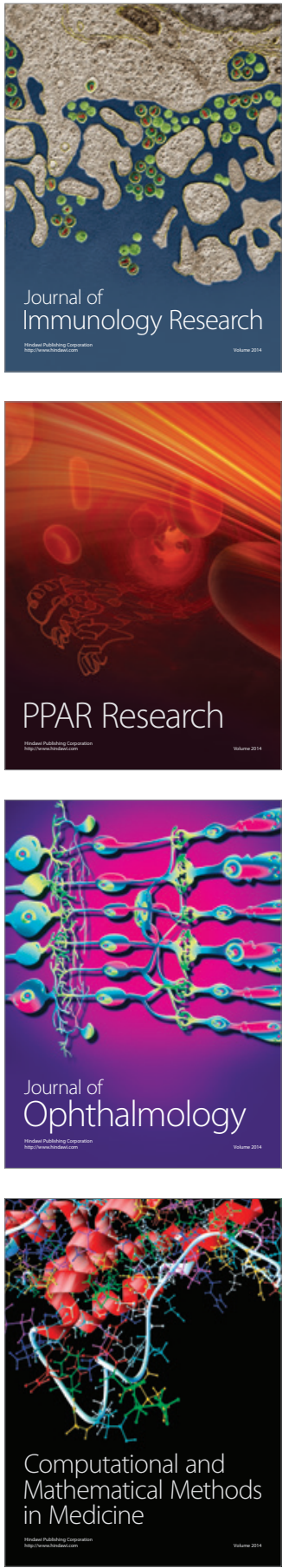

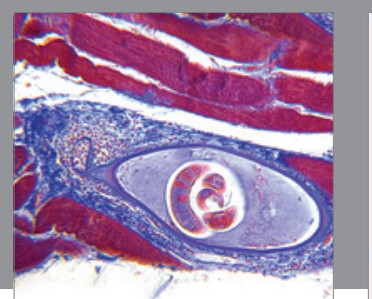

Gastroenterology Research and Practice

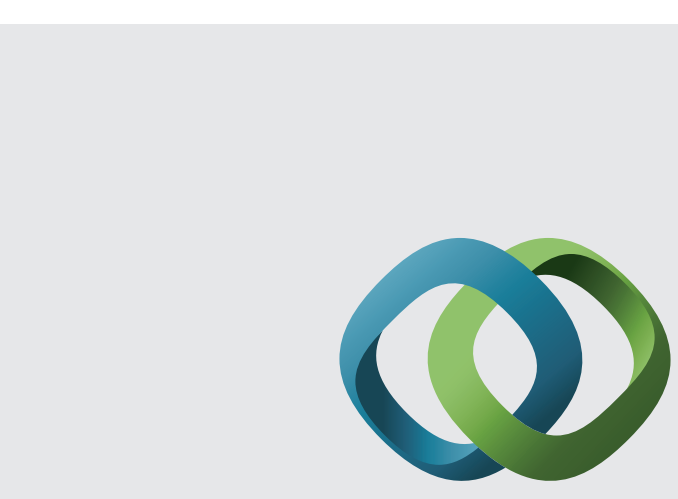

\section{Hindawi}

Submit your manuscripts at

http://www.hindawi.com
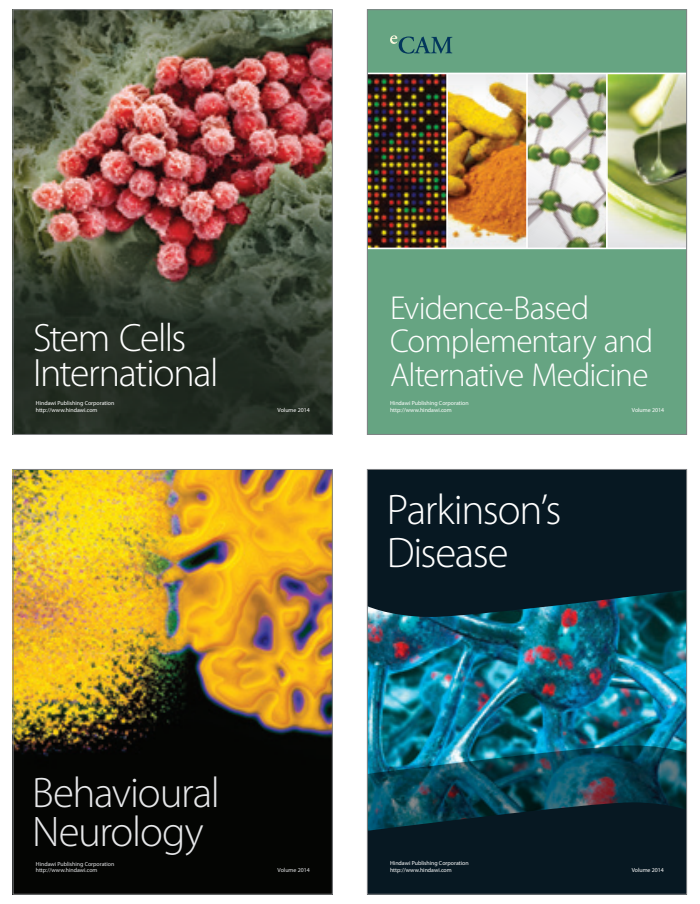
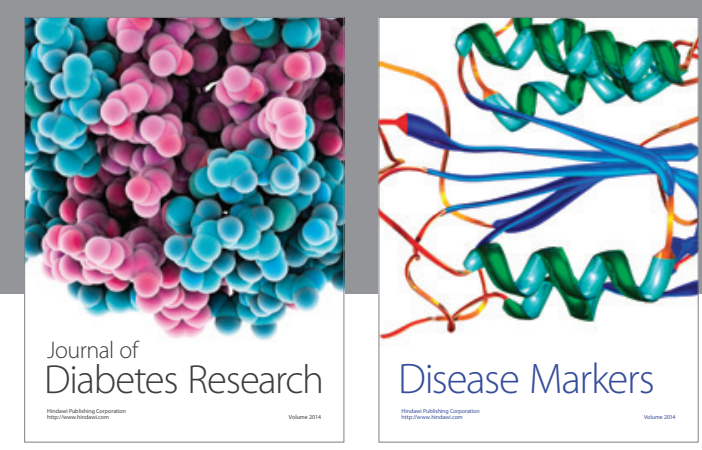

Disease Markers
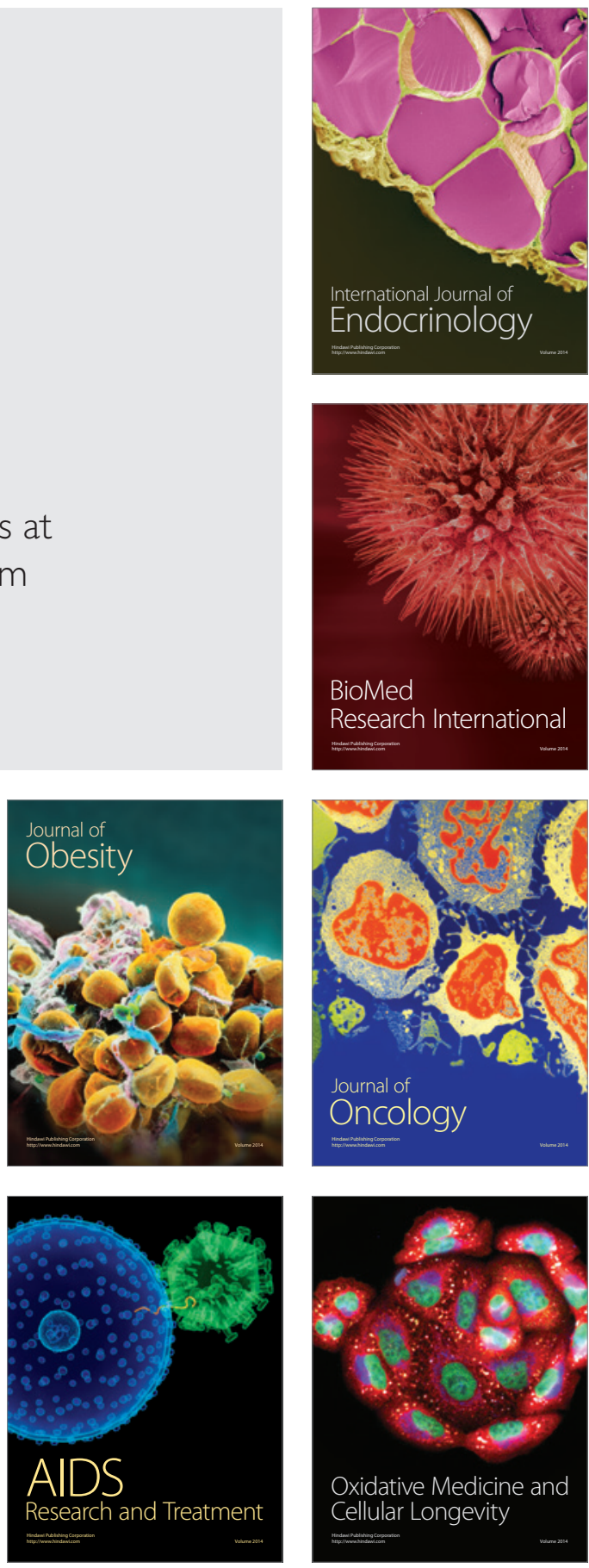